formed of the muscular coat of the bowel, but in some places that seemed to have disappeared and only the peritoneal coat remained. There was no thickening of the peritoneal coat over the ulcers but there were numerous adhesions, especially along the line of the muscular bands. There were no sloughs adherent to the base of the ulcers. The rest of the abdominal organs, with the exception of the kidneys which showed marked signs of chronic granular nephritis, appeared to be healthy. The mesenteric glands were not enlarged. A microscopical section of the bowel showed marked polypoidal changes in the mucous membrane between areas where it was entirely deficient, so that several observers thought that it was a specimen of the colitis polyposa of chronic dysentery.

It is to be regretted that this case ended fatally, but I expected that result from the very first. Emaciation had gone too far and the general weakness was so marked that the patient did not react to treatment. Anyone who had seen the condition of the colon after death would, I think, have agreed with me that recovery was impossible. The symptoms were of long duration and the condition of the mucous membrane gave the impression that the disease was of old standing. I believe that it was a typical case of simple ulcerative colitis; the signs during life and the post-mortem appearances all pointed to that diagnosis. The stools were characteristic, but there seems to have been rather more blood passed than was usual and this would account for the rapid asthenia, and as an evidence also of ulcerative activity it would account for the remarkably numerous and sudden perforations. Sudden perforations are apt to occur in this disease, although I have only been able to come across one recorded case of its occurrence. I suspected that the enemata had something to do with the perforation but no enema had been given for the two days precerling death.

Tomiting was not a marked feature of the case. was most likely reflex from the ulcerated condition of the colon, but probably the enemata increased it; anyhow this was the opinion of the patient and it was at his wish that they were discontinued. In a recent case I see it put on record that part of the contents of an enema were vomited, when given in the treatment of a case of this nature; although I saw nothing like this yet the enemata certainly seemed to increase the vomiting. The absence of any rise of temperature would be accounted for by the extreme state of prostration and the chronicity of the disease.

The case was not one of typhoid fever as there were none of the typical diagnostic signs present. Dysentery was not the cause of the symptoms as the stools were not like those of dysentery, although at the post-mortem examination the ulceration of the colon resembled to some extent the condition found in chronic dysentery. Also the patient had never been out of Yorkshire and had never, therefore, been in a position to contract that disease. The diagnosis from follicular ulceration of the colon is more difficult. The ulcers were too irregular in shape and size for only the solitary follicles to be involved and differed from the small circular ulcers with sharply cut edges met with in follicular ulceration. The Peyer's patches of the small intestine were quite normal; also there were no pellets of mucus present in the fæces as in follicular ulceration. 'The character of the ulcers exactly agreed with the description given in Hale White's cases. Thus he says, in speaking of follicular ulceration: "It will be noticed that this (i.e., follicular ulceration) is very different from the undermining ulcers exposing the muscular fibre and running together, leaving islets of polypoid mucous membrane which are so characteristic of simple ulcerative colitis."

These isolated cases are remarkable and make the question of cansation very difficult. If they were infectious we ought to hear of cases occurring in epidemics.

There was nothing in the occupation or place of residence of the man to suggest a cause nor am I able to discover that they have any influence on causation. Chronic mercurialism gives rise to a condition of the colon very like ulcerative colitis but I am convinced that this case was not one of that nature. It is unfortunate that examination of the fæces is difficult and the results are unsatisfactory; in my examination of this case I was only able to find the bacillus coli communis and some,other large bacteria.

Chronic,granular kidney was present in this case and seems to be a fairly frequent concomitant. What is the relation between the two diseases I do not know, but I think it is a point to be taken notice of and looked for in future cases. The presence of old tuberculosis I do not think of any account as the disease was practically cured. The condition of the bowel bore no resemblance to tuberculous ulceration. The man's condition on admission was such that I was unable to get any very clear history as to the state of his bowels preceding the illness. So far as he could remember he had suffered from constipation alternating with diarrhœe for a great many years. It seems therefore quite possible that at this time a catarrhal process was set up by irritant fæcal matter such as one sees in cases of fæcal impaction and that this, owing to lack of treatment, progressed to ulceration, so that finally the awful condition in which I first saw him was reached.

Treatment 1 do not regard as very satisfactory. I believe the death-rate is as high as 50 per cent. Various astringents were administered by the mouth but they seemed to have very little influence on the bleeding or diarrhoea and this appears to be the general rule in these cases. Enemata certainly did good in checking the diarrhcea and hæmorrhage and I think it will be enemata on which one must rely for treatment.

The use of solutions of nitrate of silver for this disease is not new and I believe that its use is certainly beneficial, as it is in so many catarrhal affections of other parts, and I anticipate that by the use of solutions of nitrate of silver or allied salt one wili succeed in curing, or at any rate alleviating, some of these cases. Lately a solution of argyrol has been used with success.

When the patient is strong enough to bear the operation I believe that a right-sided colotomy, objectionable as it certainly is in itself, may, by preventing the passage of fæcal raatter over the ulcerated colon and enabling treatment to be directed to the whole length of the colon, give cases a better chance of recovery, as it must be almost impossible to reach the whole length of the colon with an ordinary enema, although in some cases, especially the mild ones, where the disease is generally localised to the lower half of the colon, one ought to be able to carry out treatment by means of enemata. One or two successful cases of treatment by operation have been published and I think it should be tried more frequently.

Sheffield.

\section{A CASE OF FIBROMYOMA OF THE FUNDUS WITH CARCINOMA OF THE CERVIX UTERI.}

By JOHN PHillips, M.A., M.D. Cantab., F.R.C.P. LoND.,

OBSTETRIO PHYSTCIAN TO KING'S COLLEGE HOSPITAL AND LECTLRER ON PRACIICAI OBSTELRICS IN KING S COLLEGE.

THE patient, a single woman, aged 49 years, was first seen on May 27th, 1901, with Mr. G. L. Atkinson of Hampton, for severe menorrhagia. A large retroverted uterus with a fibroid of the size of a clenched fist in its posterior wall was found impacted below the promontory of the sacrum. Under an anresthetic this was pushed out of the pelvis and a ring pessary was inserted; it was noted at the time that the cervix was small and healthy. Six months later (on Nov. 28th) the hæmorrhages were still severe and some small cervical polypi of the size of currants were noticed projecting from the external os uteri. These were twisted off with forceps. The pathological report was "that the polypus presents a microscopic appearance which cannot be said to be definitely malignant, but is extremely suspicious." The patient was readmitted to hospital on April 8th, 1902, with the hæmorrhages much worse, the fibroid twice its former size, and her hæmoglobin percentage below 40 . Scrapings from the cervix resulted in a negative report as to malignancy and abdominal hysterectomy was performed a month later. At the operation the question of performing a panhysterectomy was discu ssed but her condition was so grave during the oreration that the idca of it was abandoned. She made a perfectly normal recovery and there was no hæmorrhage for four months. Then a slightly blood-stained discharge occasionally appeared until October, 1902, when she had a sharp flooding. Examination showed the cervix to be healthy to inspection but somewhat bulky in size. Her general condition was much improved and she declined further interference. In January, 1903, 
she had another severe flooding and on examination, although the vaginal cervix was covered by healtby mucous membrane, it was more bulky. The index finger, after a little pressure, could be pushed through the external os uteri into a slightly dilated cavity ; a small softish growth of the size of a filbert could be felt high up on the left and anterior wall. On Feb. 17th this was removed by means of polypus forceps. The report of the pathologist was as follows: "The tumour is a columnar-celled carcinoma; simple adenomatous material is also present: there are numerous hæmorrhages into the structure of the tumour."

On March 1st, with the patient in the lithotomy position, I extirpated the cervix by the vagina. It was necessary to make free liberating incisions at the vulva in order to give room for the necessary manipulations. The bladder was carefully separated from the anterior surface of the stump and the finger was introduced into the peritoneal cavity. A piece of small intestine was found closely adherent to the apex of the stump. This was carefully dissected off and the mass was removed. The operation was long and tedions and many bleeding vessels required ligature but her condition at its termination was satisfactory. The edges of the peritoneal opening were brought together by sutures, except in the centre, through which a small gauze drain was inserted. On incising longitudinally the anterior wall of the stump the conditions were found to be as follows. The cervical cavity was dilated to the size of a hazel nut but its walls were thick and apparently uninfiltrated. Projecting from the left and anterior surface near the internal os uteri was seen a small sloughing nodule, of the size of a bean, attached by a broad base. The contents of the cavity were grumous, brownish in colour, and fœtid.

I much regret now that $I$ did not persist in my original idea of performing a panhysterectomy but the patient's condition at the time was such that every minute was of importance, she being quite pulseless and scarcely breathing on leaving the operating room, and nearly a week elapsed before her pulse descended below 100 . The polypi removed at the first operation were obviously instances of tumours in a "pre-cancerous" stage, if I may so term it, and, although at a subsequent examination no evidence of malignancy could be made out in the scrapings, still I should not hesitate should I meet with a similar case to risk the more serious operation of panhysterectomy. The patient has since reported herself (18 months after the last operation) and examination indicated no signs of recurrence.

This case shows many points of interest. The most important is the deceptive condition of the cervix on its external aspect. This remained quite healthy up to the day of operation and, except for general hypertrophy, no one would have been led to suspect the nature of the disease going on in its cavity. The microscopical examination was not satisfactory in spite of many slides being examined and although the possibility of malignant disease existed all through there was never sufficient evidence to subject the patient to a grave operation.

Brook-street, w.

\section{THE PROBLEM OF THE MORALLY DEFECTIVE. ${ }^{1}$}

By W. A. PotTs, B.A. Cantab., M.D. Edin. \& Birm., M.R.C.S. ENG.,

CHAIRMAN OF THE BIRMINGHAM AF'TER-CARE COMMITTEE.

THIs problem is inseparably connected with that of the eeble-minded. When I say that feebleness of mind, weakness of morals, and a poor standard of physical health go hand-in-hand I am but expressing a truism. There are some-not in such an audience as this-but there are some who have not yet realised either the truth of what I have said or its logical application. I only wish that those who have failed to do so had been with me when I recently paid a series of visits to a girls' night shelter. I would just like to tell you of the first 12 cases as I found them. The first woman was evidently suffering from consumption-both parents and one brother had died from that disease. The second, who was a

1 A paper read at a combined conference of the National Association for the Feeble-minded and the National Special Schools Union on
Oct. 13th, 1904. drunkard and had deserted both her husband and her. children, was markedly neurotic and had suffered from St. Vitus's dance at ten years of age. The third was in all respects normal. The fourth was a deaf microcephalic, which. as you know, is a well-known type of mental defect The fifth was a blend of the neurotic and microcephalic types and had at one time spent two years in a lunatic asylum. The sixth showed no congenital defect but nowat 40 years of age-her health was ruined by drink. The seventh and eighth were poor feeble creatures though without obvious physical stigmata. The ninth suffered from. persistent bad memory, a defect probably due to a severe. injury to the head with a spade at two years of age. The tenth was well developed physically and intellectually but had twice been in prison for theft; she was the daughter of a drunken loafer. The eleventh was normal but the twelfth, a young girl who had been wandering away from home for a week, was a Mongolian, another well-recognised type of mental defect, and in addition was suffering from heart disease. In short, among the 12 who had found their way into a shelter for destitute girls there were only two norma individuals. Well, I give you these cases as I found them : they speak for themselves.

The feeble-minded are from their very nature feeble in all respects ; they show their weakness in their moral qualities: they are therefore specially susceptible to bad influences. For this reason the Birmingham After-care Committee has been so urgent in demanding either boarding-school or colony accommodation for such of the feeble-minded as come from bad homes. Miss Dendy has demonstrated that far better results are obtained by removing the feeble-minded from bad homes and from the streets, where they learn notbing that is good and all that is bad. In certain cases we find that while there is apparently little or no in. tellectual or physical weakness, yet there is marked moral defect. Take as an example the girl I have already mentioned as having twice been in prison for theftonce for stealing a bicycle and once for stealing a cheque. A good-looking, healthy, well-developed girl, ready to answer all questions intelligently; judging from appearances. only I think many mistresses would be ready to engage her. She has, however, stayed in one place two days, in another ten minutes, leaving because some trifling matter displeased her. When she stole the cheque from her mistress she was sharp enough to think it might not be cashed to a young girl, so she altered the Mrs. to Miss, a change which was at once detected by the cashier at the bank. In case there is any particularly charitable lady present I may say that this: girl is now anxious to obtain another situation. In degenerates such as this the congenital tendency has spent its. chief force on the moral centres, so that they are spoken of as cases of moral insanity. They are without sense of honour or shame; they are obstinate, lazy, and selfish. Their tendency to go wrong is out of all proportion to the temptations to which they are exposed. Some-possibly manyought to be classed among the feeble-minded. For instance, think of a girl, 16 years of age, brought to see me by her father two days ago ; the mother died from consumption and an aunt is now in a lunatic asylum; two sisters have also died from consumption. The girl showed no physical sign of defect but was dull and stupid with a significantly vacant smile; she reads and writes with difficulty and is no good at figures. The most marked characteristic is a regular kleptomania. She steals anything and everything. She stole a pocket-knife and ripped open her brothers' and sisters' moneyboxes, spent some of the money on sweets and gave the rest away to the first children she met in the road. She is such a mixture of cunning and stupidity that when her father gave her a penny to buy a penny bun she turned back at the shop-door to ask him what change she ought to get. Such cases require care and training and are amenable to proper: treatment, though I am ready to admit that good results are obtained but slowly. We generally find on investigation. that there is deficient nerve energy ; the habitual eriminal is sometimes capable of great exertion for a time but not of regular systematic work. Such cases should be treated in an industrial home, separated, however, from the ordinary feeble-minded. The home should be under medical supervision ; the medical treatment should be hygienic-unstimulating food, fresh air, baths, and exercise.

Now you must not think that I am going to excuse and explain away all wrong-doing. We live in an age far too ready to do that. I at least am not one of those who think that because a man is in a lunatic asylum he should be at 